\title{
Corynespora cassiicola and Stemphylium lycopersici infection and disease development on tomatoes in Argentina
}

\author{
Mario Emilio Ernesto Franco ${ }^{1,2}$ - Silvina Marianela Yanil López ${ }^{1,2}$. \\ Gustavo Lucentini $^{1,3}$ • Maria Inés Troncozo ${ }^{2}$ - Mario Carlos Nazareno Saparrat ${ }^{2,4,5,6}$. \\ Blanca Lía Ronco ${ }^{1}$ • Pedro Alberto Balatti ${ }^{1,3,6}$
}

Received: 20 December 2016/Accepted: 7 August 2017/Published online: 16 August 2017

(C) Australasian Plant Pathology Society Inc. 2017

\begin{abstract}
Two pathogens were isolated from tomatoes with severe chlorosis and necrosis in northwestern Argentina. Monosporic cultures were morphologically characterised and molecularly identified as Stemphylium lycopersici and Corynespora cassicola. This is the first report of C. cassiicola infecting tomato in Argentina.
\end{abstract}

Keywords Stemphylium lycopersici · Corynespora cassiicola - Tomato gray leaf spot - Tomato target leaf spot . Solanum lycopersicum $\cdot$ Simultaneous infection

Tomato (Solanum lycopersicum) is a major vegetable crop worldwide due to its nutritional and economic importance (Jones et al. 2014). Like other cultivated plants production is threatened by pests and diseases. Approximately 76 fungal

Pedro Alberto Balatti

pbalatti@gmail.com

1 Centro de Investigaciones de Fitopatología, Facultad de Ciencias Agrarias y Forestales, Universidad Nacional de La Plata, La Plata, 1900 Buenos Aires, Argentina

2 Consejo Nacional de Investigaciones Científicas y Técnicas, Buenos Aires, Argentina

3 Comisión de Investigaciones Científicas de la Provincia de Buenos Aires, Buenos Aires, Argentina

4 Instituto de Fisiología Vegetal, Facultad de Ciencias Naturales y Museo-Facultad de Ciencias Agrarias y Forestales, Universidad Nacional de La Plata, La Plata, 1900 Buenos Aires, Argentina

5 Instituto de Botánica Carlos Spegazzini, Facultad de Ciencias Naturales y Museo, Universidad Nacional de La Plata, La Plata, 1900 Buenos Aires, Argentina

6 Cátedra de Microbiología Agrícola, Facultad de Ciencias Agrarias y Forestales, Universidad Nacional de La Plata, 327, La Plata, 1900 Buenos Aires, CC, Argentina species are known to be associated with tomatoes (Farr and Rossman 2016). In Argentina the most important fungal diseases affecting tomato are gray mold, leaf mold, powdery mildew, gray leaf spot, Fusarium wilt, Fusarium crown and root rot, Septoria leaf spot, Verticillium wilt, early blight, late blight and Sclerotinia basal stem canker (Argerich and Troilo 2011)

During the first half of 2015, severe leaf chlorosis and necrosis followed by defoliation was observed on tomato plants growing in Orán, Salta province, northwest Argentina. To isolate the causal agent, 16 pieces of diseased leaf material were collected from each of three plant samples and were disinfected with $1 \% \mathrm{NaOCl}$ for $1 \mathrm{~min}$, rinsed with sterile distilled water, plated on potato dextrose agar (PDA) and incubated at $25^{\circ} \mathrm{C}$. After one week, we observed the development of two fungal colonies in plates coming from a single plant sample, with clearly different macroscopic and microscopic characteristics. In order to obtain monosporic strains, conidial suspensions were prepared, plated on PDA and incubated at $25^{\circ} \mathrm{C}$ for $72 \mathrm{~h}$. Then, a colony from each culture was transferred to a new PDA plate and incubated at $25^{\circ} \mathrm{C}$ for a week. Monosporic cultures of both strains were deposited in the $\mathrm{La}$ Plata Spegazzini Collection (LPSC 1246 and LPSC 1245) housed at Instituto de Botánica Spegazzini, Universidad Nacional de La Plata, Argentina.

Cultural and morphological features of the strains were analysed using 7 days-old cultures grown on PDA at $25^{\circ} \mathrm{C}$ in continuous darkness. Strain LPSC 1246 developed cottonyraised colonies with a mean diameter of $62.67 \pm 2.5 \mathrm{~mm}$ and undulate margins; they were characterised by a heterogeneous mycelial pigmentation (white, strong orange and greyish red) and by the presence of a vivid orange pigment that diffused into the culture medium (Table 1 and Fig. 1a, b). Conidiophores were pale brown, short and simple, branched or occasionally unbranched, 2-7 septate, $3.6 \mu \mathrm{m}$ wide, with terminal conidiogenous cells that were distinctly swollen 
Table 1 Cultural characteristics of strains grown on PDA

\begin{tabular}{|c|c|c|c|c|c|c|c|c|}
\hline \multirow[t]{2}{*}{ Strain } & \multicolumn{7}{|c|}{ Colony character } & \multirow{2}{*}{$\begin{array}{l}\text { Media } \\
\text { pigmentation }{ }^{d}\end{array}$} \\
\hline & Diameter $^{\mathrm{a}}$ & Obverse Color $^{\mathrm{d}}$ & Reverse Color ${ }^{\mathrm{d}}$ & Texture & Elevation & Margin & Zonation & \\
\hline LPSC 1246 & $69.31^{\mathrm{b}} \pm 3.66^{\mathrm{c}}$ & $\begin{array}{l}\mathrm{W}(\mathrm{N} 9)-\mathrm{SO}(5 \mathrm{YR} 7 / 12) \text { - GR } \\
(10 \mathrm{R} 5 / 2)\end{array}$ & VRO (10R 5/16) - B (N 9) & Cottony & Raised & Undulate & Absent & VO (2.50YR 6/16) \\
\hline LPSC 1245 & $64.07 \pm 2.25$ & LGB (7.5YR 6/2) - W (N 9) & $\begin{array}{l}\text { DGRB (2.5YR 2/2) - LYP } \\
\quad(2.5 \text { YR } 8 / 4)\end{array}$ & Cottony & Raised & Entire & Concentric & Absent \\
\hline
\end{tabular}

${ }^{\text {a }}$ Values of 13 replicates taken from 7 day-old cultures grown on PDA at $25^{\circ} \mathrm{C}$ in darkness

${ }^{\mathrm{b}}$ Mean

${ }^{\mathrm{c}}$ Standard deviation

${ }^{\mathrm{d}}$ Colors were designated according to the Munsell Colour Order System as implemented in the Virtual Colour Atlas v. 2.0.0720 web application (Virtual Colour Systems LTD 2013): B Black, DGRB Dark greyish reddish brown, GR Greyish red, $L G$ Light grey, $L G B$ Light greyish brown, $L Y P$ Light yellowish pink, $S O$ Strong orange, $V O$ Vivid orange, $V R O$ Vivid reddish orange, $W$ White

(7.2 $\mu \mathrm{m}$ wide) and with percurrent proliferation. Conidia were oblong, rounded or pointed at the apex with a prominent scar at the rounded base. They had 3 constrictions and a verruculose cell wall ornamentation. They were light brown in color and measured $55.30 \pm 3.25 \mu \mathrm{m}$ in length and $18.67 \pm 1.00 \mu \mathrm{m}$ in width (Table 2 and Fig. 2a, b). All these characteristics are similar to those described for representatives of the genus Stemphylium (Ellis 1971). The other strain, LPSC 1245, developed colonies with a mean diameter of
$66.33 \pm 3.21 \mathrm{~mm}$ (Table 1 and Fig. 1c, d). Although it also exhibited cottony and raised colonies, they differed in having entire margins and concentric zonation, alternating white and light greyish brown colors. Conidiophores were paleolivaceous in color, un-branched or occasionally branched, $3.6 \mu \mathrm{m}$ wide, straight to slightly curved, 1-8 septate, smooth-walled and conidiogenous cells (3.6-4.80 $\mu \mathrm{m}$ wide) which were terminal and with percurrent proliferation. Furthermore, conidia were elongated, obclavate to cylindrical
Fig. 1 Cultural characteristics of strains LPSC 1246 (a and b, obverse and reverse, respectively) and LPSC 1245 (c and d, obverse and reverse, respectively). Pictures show 7-day old cultures of the organisms grown on PDA at $25^{\circ} \mathrm{C}$ in continuous darkness
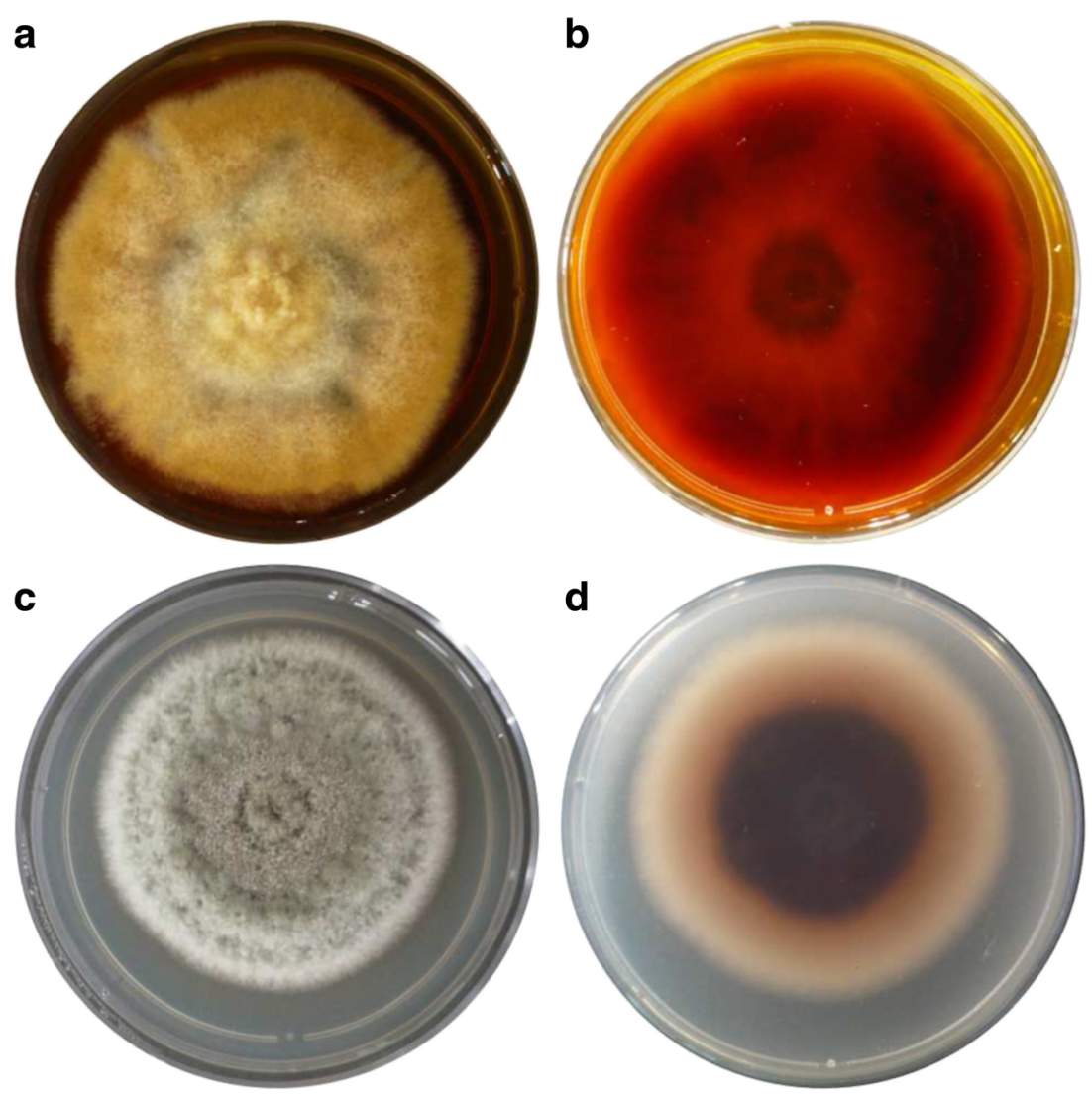
Table 2 Morphological characteristics of conidia

\begin{tabular}{lllll}
\hline \multirow{2}{*}{ Strain } & Conidia $^{\mathrm{a}}(\mu \mathrm{m})$ & & \\
\cline { 2 - 5 } & Length $(\mathrm{L})$ & Width $(\mathrm{W})$ & Average L:W ratio & Transverse septa/pseudo-septa \\
\hline LPSC 1246 & $64.80-480^{\mathrm{b}}$ & $19.20-16.80$ & $3.38-2.75$ & $3-2$ \\
& $55.30^{\mathrm{c}} \pm 3.25^{\mathrm{d}}$ & $18.67 \pm 1.00$ & $2.97 \pm 0.19$ & $2.84 \pm 0.37$ \\
LPSC 1245 & $187.20-76.80$ & $7.20-4.80$ & $39.00-14.00$ & $4-0$ \\
& $128.02 \pm 27.83$ & $7.06 \pm 0.58$ & $18.26 \pm 4.56$ & $1.30 \pm 0.89$ \\
\hline
\end{tabular}

${ }^{\text {a }}$ Values of 50 replicates taken from 7 day-old cultures grown on PDA at $25^{\circ} \mathrm{C}$ in darkness

${ }^{\mathrm{b}}$ Range

${ }^{\mathrm{c}}$ Mean

${ }^{\mathrm{d}}$ Standard deviation

with up to 4 pseudo-septa and a thick cell wall. They were pale olivaceous in color and were $128.02 \pm 27.83 \mu \mathrm{m}$ long and $7.06 \pm 0.58 \mu \mathrm{m}$ wide (Table 2 and Fig. 2c, d). These cultural and morphological characteristics are typical of representatives of species of Corynespora (Wei 1950).

A molecular analysis was carried out in order to confirm identification of the strains. We studied both the Internal transcribed Spacer (ITS) region and the glyceraldehyde-3phosphate dehydrogenase ( $g p d$ ) partial sequence of the putative Stemphylium strain LPSC 1246 and ITS region of tentative Corynespora strain LPSC 1245. Total genomic DNA was extracted from axenic cultures by means of the Wizard Genomic DNA Purification Kit (Promega, Madison, WI). A Polymerase chain reaction (PCR) was carried out to amplify the ITS region with the universal primers ITS1 $\left(5^{\prime}\right.$-TCCG TAGGTGAACCTGCG-3') and ITS4 (5'-TCCT CCGCTTATTGATAT-3') (White et al. 1990) and the gpd partial sequence with the newly designed primers GPDF (5'GACATTGTCGCCGTGAAC-3') and GPDR (5'-ACTC GACGACGTAGTAGG-3').
The design of the latter pair of primers was based on gpd sequences from Stemphylium spp. deposited in the Gen-Bank database and was done using the Geneious 9.1.2 software (Biomatters Ltd., Auckland, New Zealand). The targeted sequence is $322 \mathrm{bp}$ long and spans from the $3^{\prime}$-end of the third exon to the 5'-end of the fourth (Locus tag: TW65_04473; Protein accession number KNG48731). The conditions for the PCR were developed based on the web tool Optimase and ProtocolWriter (Transgenomic, Inc.). The desired amplicon was useful in discriminating tomato gray leaf spotassociated Stemphylium spp., because polymorphisms were located within the third intron. In the current study, both reactions were performed in a $15 \mu \mathrm{l}$ reaction mixture containing 50 ng of template DNA, $0.3 \mu \mathrm{M}$ of each forward and reverse primer, $1.5 \mu \mathrm{l} 10 \mathrm{X}$ reaction buffer $(500 \mathrm{mM} \mathrm{KCl} ; 100 \mathrm{mM}$ Tris-HCl, pH 9.0 a $25^{\circ} \mathrm{C} ; 1 \%$ Triton X-100), $1.5 \mathrm{mM} \mathrm{MgCl} 2$, $0.2 \mathrm{mM}$ dNTPs and 1 unit of Taq polymerase (Inbio Highway ${ }^{\circledR}$, Buenos Aires, Argentina). The amplification of the ITS was performed using the following profile: $5 \mathrm{~min}$ at $94{ }^{\circ} \mathrm{C}$ followed by 33 cycles of $1 \mathrm{~min}$ at $94{ }^{\circ} \mathrm{C}, 45 \mathrm{~s}$ at $56{ }^{\circ} \mathrm{C}$
Fig. 2 Conidia of strains LPSC 1246 (a and b) and LPSC 1245 (c and d) from 7-day old cultures grown on PDA at $25^{\circ} \mathrm{C}$ in continuous darkness. Scale bar $=30 \mu \mathrm{m}$
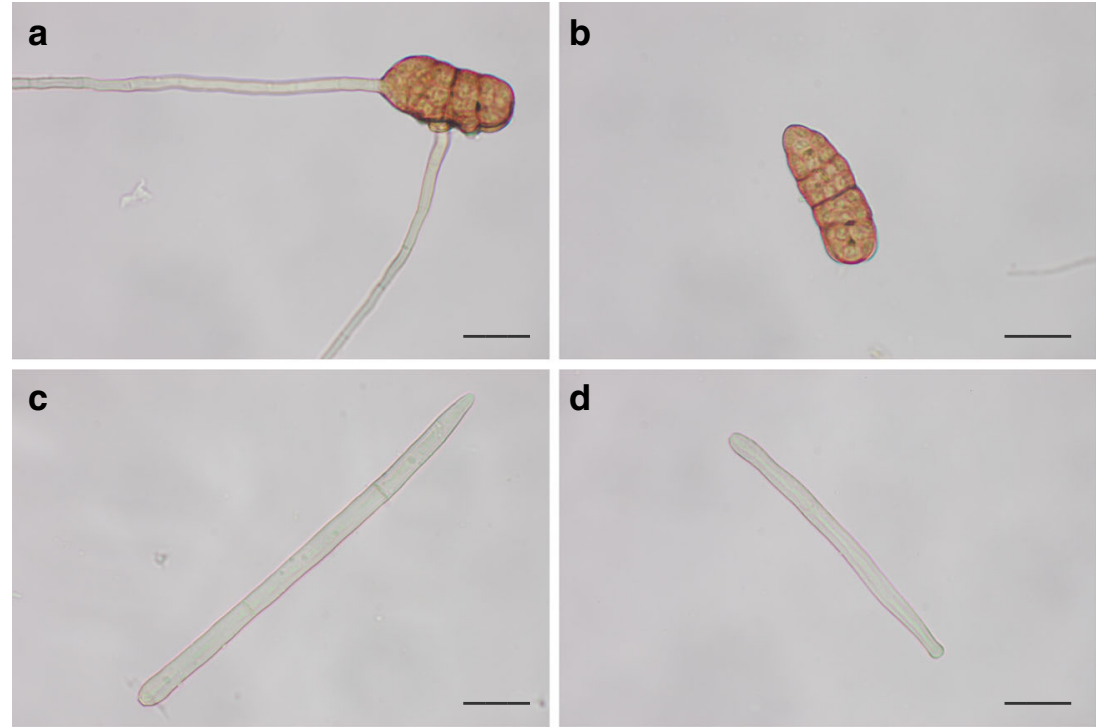

d 
Fig. 3 Maximum likelihood tree of Stemphylium/Pleospora inferred from the concatenated ITS-gpd nucleotide sequences. Nucleotide sequences of Alternaria alternata were used as outgroup. Nucleotide sequences generated in this study are in bold type letter. Numbers at the nodes represents bootstrap support values as a percentage of 1000 replicates. The scale bar represents the average number of nucleotide substitutions per site

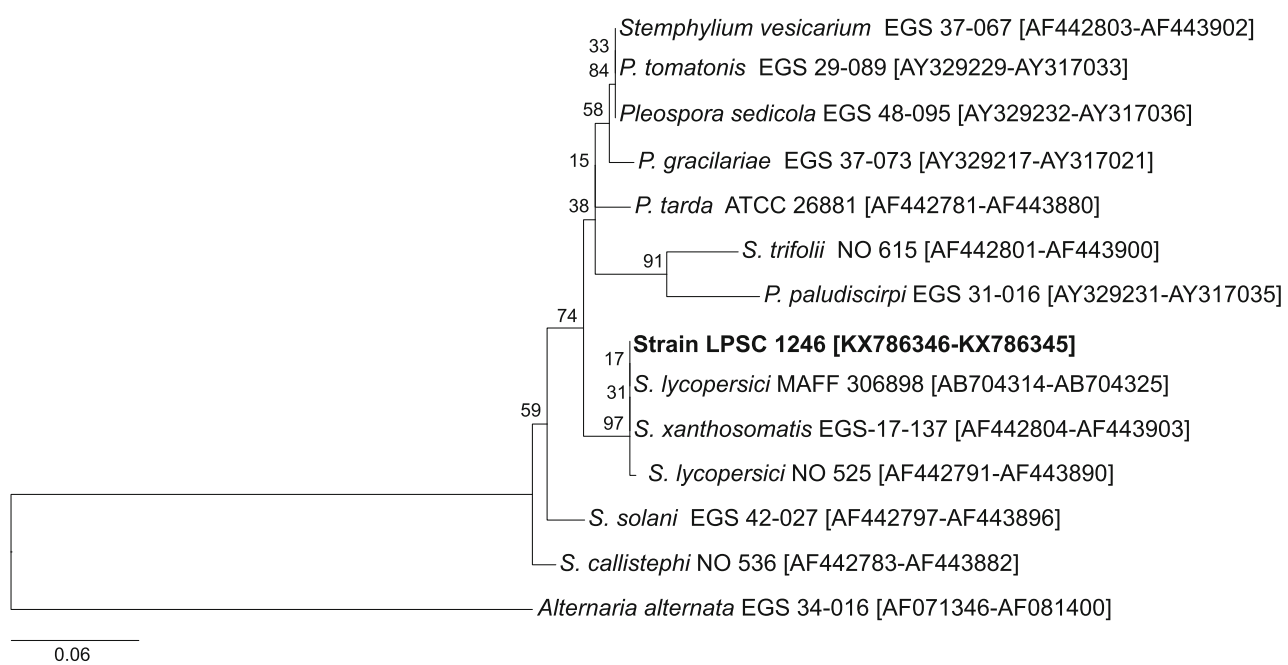

and $1 \mathrm{~min}$ at $72^{\circ} \mathrm{C}$, followed by a final extension step of $72^{\circ} \mathrm{C}$ for $5 \mathrm{~min}$. The gpd amplification was performed using the following program: $5 \mathrm{~min}$ at $94{ }^{\circ} \mathrm{C}$ followed by 30 cycles of $30 \mathrm{~s}$ at $94{ }^{\circ} \mathrm{C}, 30 \mathrm{~s}$ at $56^{\circ} \mathrm{C}$, and $30 \mathrm{~s}$ at $72{ }^{\circ} \mathrm{C}$ and a final extension that consisted on $5 \mathrm{~min}$ at $72{ }^{\circ} \mathrm{C}$. Sequences were BLASTed (Basic Local Alignment Search Tool) against the non-redundant nucleotide collection database of GenBank. The ITS sequence of strain LPSC 1246 showed 100\% identity with Stemphylium spp., while its gpd sequences revealed $100 \%$ identity with S. lycopersici strain MAFF 306898 (GenBank accession number AB704325). The ITS sequence of strain LPSC 1245 showed $100 \%$ identity with C. cassiicola strain AS54 (GenBank accession number FJ852576). The resultant ITS and gpd sequences of strain LPSC 1246 were deposited in the DDBJ/EMBL/GenBank under the accession numbers KX786346 and KX786345, respectively. The ITS sequence of strain LPSC 1245 was submitted to the same databases under accession number KX786348. In order to establish the taxonomic position of the strains, a phylogenetic analysis was carried out using the concatenated ITS-gpd sequence of strain LPSC 1246 and the ITS sequence of strain LPSC 1245, alongside with nucleotide sequences of related taxa obtained from GenBank. Sequences were aligned with Geneious 9.1.2 (Biomatters Ltd., Auckland, New Zealand) using the default parameters of the ClustalW algorithm. The resultant alignments were automatically curated with Gblocks 0.91b (Castresana 2000) using default settings except for the minimum length of a block, which was set to 2 . The best substitution model was determined using jModelTest 2.1.7 (Darriba et al. 2012). Matrices were analysed using Maximum Likelihood estimation in PhyML 3.0 (Guindon and Gascuel 2003) and the support of the trees was 1000 bootstrap replications (Felsenstein 1985). Our results showed that strain LPSC 1246 clustered with $S$. lycopersici MAFF 306898 , S. lycopersici NO 525 and also with S. xanthosomatis EGS-17-137 (Fig. 3). Regarding this, both S. lycopersici and S. xanthosomatis shared morphological characteristics, had identical ITS sequences and could differ
Fig. 4 Maximum likelihood tree of Corynespora inferred from ITS nucleotide sequences. Nucleotide sequences of Alternaria alternata were used as outgroup.

Nucleotide sequences generated in this study are in bold type letter. Numbers at the nodes represents bootstrap support values as a percentage of 1000 replicates. The scale bar represents the average number of nucleotide substitutions per site

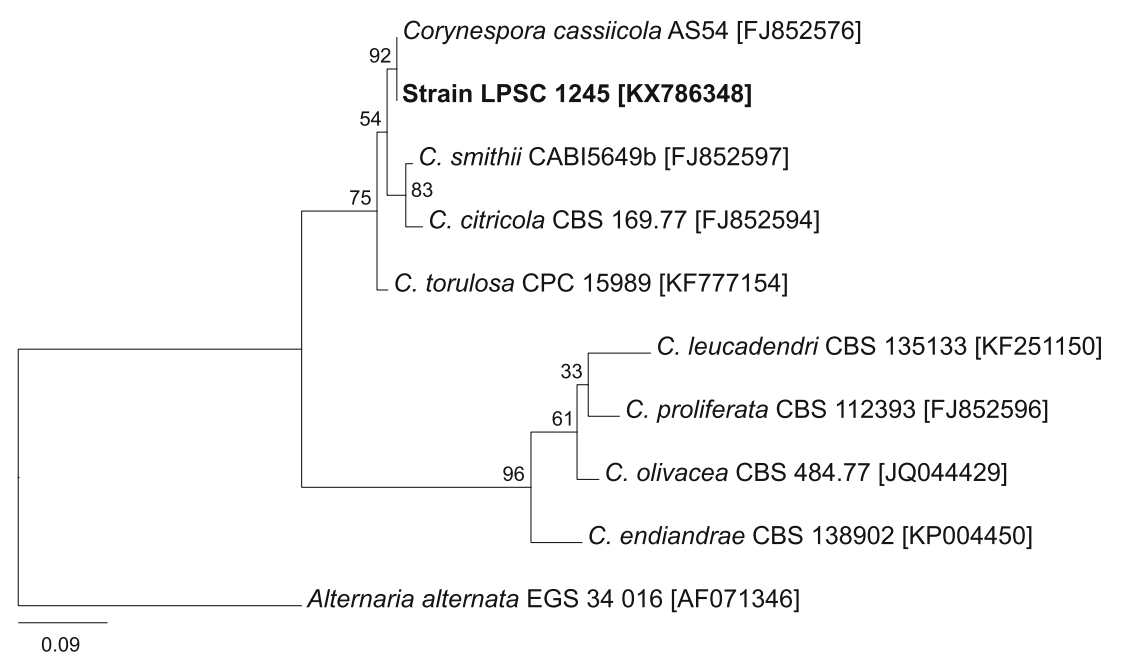


Fig. 5 In vitro pathogenicity test. Disease symptoms of tomato cv. Elpida detached leaflets 7 days post inoculation with conidial suspensions of strains LPSC 1246 (b) and LPSC 1245 (c). Control leaflets were treated with a sterile Triton X-100 0.01\% solution (a)
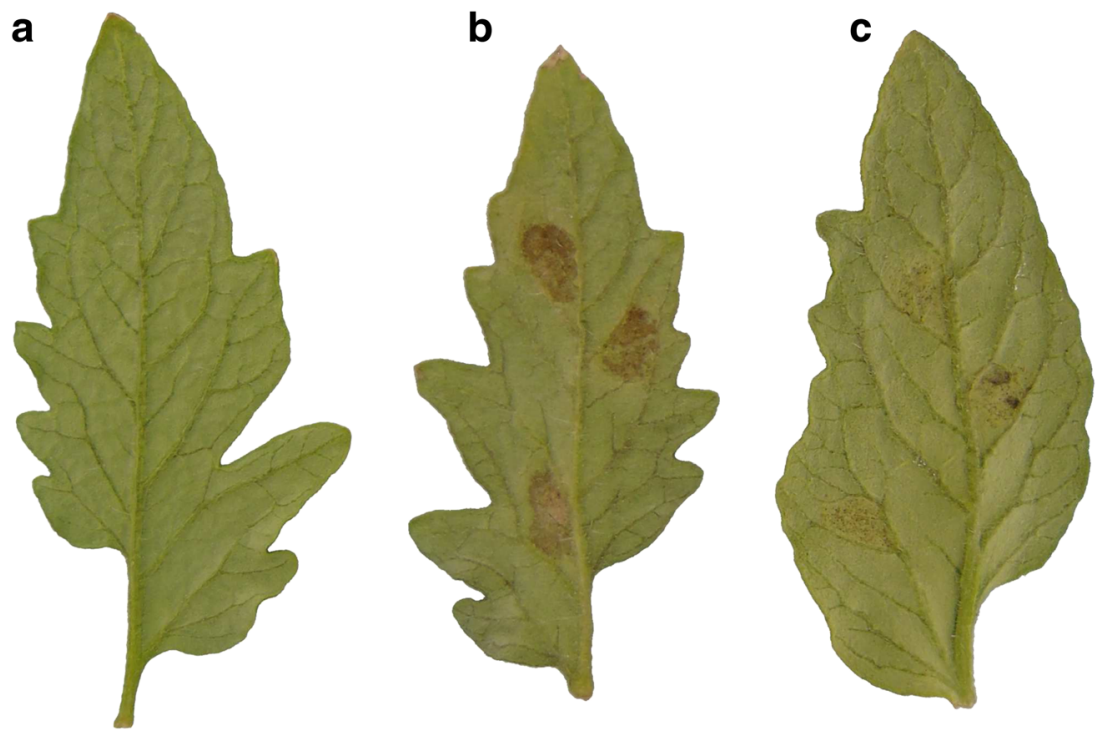

in only one nucleotide within their $g p d$ sequences. In fact, this led to the suggestion that $S$. xanthosomatis may be a synonym of $S$. lycopersici with intra-specific variation (Câmara et al. 2002; Hong et al. 2012). On the other hand, LPSC 1245 clustered with Corynespora cassiicola AS54 (Fig. 4).

Pathogenicity tests of the strains were performed on tomato cv. Elpida detached leaflets that were placed with the adaxial side down, on a filter paper moistened with sterile water inside a Petri plate. They were inoculated at three equidistant points with $30 \mu \mathrm{l}$ of a conidial suspension of $10^{5}$ conidia.ml $^{-1}$ in Triton X-100 $0.01 \%$. Controls consisted of leaflets treated with the sterilised Triton X-100 solution. Symptoms developed by strain LPSC 1246 and LPSC 1245 were visible 2 and 3 days post inoculation, respectively. No symptoms were observed on non-inoculated control leaflets (Fig. 5). Each fungal strain was re-isolated from inoculated leaflets, thus fulfilling Koch's postulates.

We demonstrated that diseased tomato materials collected in Orán, Salta, were infected by S. lycopersici and C. cassiicola. Stemphylium lycopersici is one of the etiological agents of tomato gray leaf spot, a disease whose incidence, severity and geographical distribution is increasing in Argentina. Indeed, this is the first report of tomato gray leaf spot caused by $S$. lycopersici in the tomato-growing region of northwestern Argentina. Furthermore, even though C. cassiicola has been found to induce target leaf spot disease in several hosts worldwide, it has never been associated with tomato in Argentina. There it has been found affecting high bush blueberry (Vaccinium corymbosum L.) and soybean (Glycine max L.) (Hongn et al. 2007, Ploper 2014, Sistema Nacional Argentino de Vigilancia y Monitoreo de plagas SENASA 2016). Considering all this together, it is possible that the strain of $C$. cassiicola belongs to a tomato-pathogenic population that was recently introduced into northwestern Argentina. However, we cannot rule out the existence of a pre-established population behaving as an opportunistic pathogen that infects stressed tomato plants, such as those preinfected with $S$. lycopersici. Future studies should be aimed at analysing the genetic diversity among $C$. cassiicola strains from Argentina in order to test whether the current C. cassiicola strain belongs to a new population or if it is related to those strains already described and infecting other species such as soybean and high bush blueberry.

Acknowledgements This research was partially supported by the Agencia Nacional de Promoción Científica y Tecnológica (ANPCyT) of the Ministro de Ciencia, Tecnología e Innovación Productiva through the projects PICT 2012-2760 (Pedro Alberto Balatti) and PICT 2015-1620 (Mario Carlos Nazareno Saparrat). The Universidad Nacional de La Plata Subsidio 2016 and the CICBA Subsidio 2015 funded the project

\section{References}

Argerich C, Troilo L (2011) Manual de Buenas Prácticas Agrícolas en la cadena de tomate FAO-INTA, Ministerio de Agricultura, Ganadería y Pesca, Argentina

Câmara MP, O’Neill NR, van Berkum P (2002) Phylogeny of Stemphylium spp. based on ITS and glyceraldehyde-3-phosphate dehydrogenase gene sequences. Mycologia 94(4):660-672. doi:10. $1080 / 15572536.2003 .11833194$

Castresana J (2000) Selection of conserved blocks from multiple alignments for their use in phylogenetic analysis. Mol Biol Evol 17(4): 540-552. doi:10.1093/oxfordjournals.molbev.a026334

Darriba D, Taboada GL, Doallo R, Posada D (2012) jModelTest 2: more models, new heuristics and parallel computing. Nat Methods 9(8): 772-772. doi:10.1038/nmeth.2109

Ellis MB (1971) Dematiaceous hyphomycetes. Commonwealth Mycological Institute, Kew

Farr DF, Rossman AY (2016) Fungal databases. Systematic mycology and microbiology laboratory. ARS, USDA http://nt.ars-grin.gov/ fungaldatabases/. Accessed Nov 2016

Felsenstein J (1985) Confidence limits on phylogenies: an approach using the bootstrap. Evolution 39(4):783-791. doi:10.1111/j.1558-5646. 1985.tb00420.x 
Guindon S, Gascuel O (2003) A simple, fast, and accurate algorithm to estimate large phylogenies by maximum likelihood. Syst Biol 52(5): 696-704. doi:10.1080/10635150390235520

Hong SK, Choi HW, Lee YK, Shim HS, Lee SY (2012) Leaf spot and stem rot on Wilford swallowwort caused by Stemphylium lycopersici in Korea. Mycobiology 40(4):268-271. doi:10.5941/ MYCO.2012.40.4.268

Hongn S, Ramallo A, Baino O, Ramallo JC (2007) First report of target spot of Vaccinium corymbosum caused by Corynespora cassiicola. Plant Dis 91(6):771-771. doi:10.1094/PDIS-91-6-0771C

Jones JB, Jones JP, Stall RE, Zitter TA (2014) Compendium of tomato diseases and pests. American Phytopathological Society Press, St. Paul
Ploper LD (2014) Importancia de las enfermedades que afectan las partes áreas de las plantas de soja en la República Argentina. In 'Libro de Resúmenes del $3^{\circ}$ Congreso Argentino de Fitopatología. San Miguel del Tucumán, Tucumán, p. 139

Sistema Nacional Argentino de Vigilancia y Monitoreo de plagas SENASA (2016) http://www.sinavimo.gov.ar/. Accessed Nov 2016

Wei CT (1950) Notes on Corynespora. Mycol Pap 34:1-10

White TJ, Bruns T, Lee S, Taylor JW (1990) Amplification and direct sequencing of fungal ribosomal RNA genes for phylogenetics. PCR protocols: a guide to methods and applications 18(1):315-322 